\title{
Rural High School Students' Sexual Behavior and Self-Esteem
}

\author{
Brian Unis' ${ }^{1}$ Inger Johansson 1,2, Christina Sällström1 \\ ${ }^{1}$ Faculty of Health, Science and Technology, Department of Health Sciences, Karlstad University, Karlstad, \\ Sweden \\ ${ }^{2}$ Faculty of Health Care and Nursing, Gjoevik University College, Gjoevik, Norway \\ Email: brian.unis@kau.se, inger.johansson@kau.se, christina.sallstrom@kau.se
}

Received 15 December 2014; accepted 31 December 2014; published 15 January 2015

Copyright (@ 2015 by authors and Scientific Research Publishing Inc.

This work is licensed under the Creative Commons Attribution International License (CC BY).

http://creativecommons.org/licenses/by/4.0/

cc) (i) Open Access

\section{Abstract}

Background: Negative consequences for sexual health may be caused by risky sexual behavior related to attitudes, norms and self-efficacy regarding sexuality. Research has not resulted in a consensus on the associations between self-esteem and adolescents' sexual behavior. Aims and Objectives: The aim of the study was to describe high school students' sexual behavior and self-esteem, along with investigating the relationship of attitudes, norms, self-efficacy, and self-esteem to sexual risk behavior. Another aim was to describe and compare gender differences in self-esteem and sexual risk behavior in high school students in a rural context. Methodological Design: A crosssectional design was used. The participants were 139 high school students, 16 to 18 years of age, sample size was decided by power calculation, and systematic randomized sampling was used. The students replied to a questionnaire about self-esteem, factors affecting sexual risk behavior, and sexual behavior. Results: Swedish high school students reported having few sexual partners, a low use of alcohol along with sex, yet a low consistency in condom use. The students reported both high basic self-esteem as well as earned self-esteem. Basic self-esteem was higher for male students while earned self-esteem was higher for female students. Significant correlations were found between self-esteem and some factors affecting sexual risk behavior related to condom use. Conclusion: High school students exhibited positive sexual behaviors and high levels of selfesteem, yet they put themselves at risk by inconsistent use of condoms. Our findings can contribute the need of to an awareness of the role self-esteem, attitudes, norms and self-efficacy plays in adolescents' sexual behavior. Nurses working at the youth clinics are in a key position to discuss sexual health issues with adolescents to promote healthy outcomes in sexual health.

\section{Keywords}

Reproductive Health, Sexual Behavior, Self-Esteem, Adolescent Health 


\section{Introduction}

An increase in high risk sexual behavior has been observed in a number of European countries, but due to few countries having conducted population surveys, there is still much not known about patterns of sexual behavior and the data which are available are not always comparable [1]. Sexual health can be defined as a state of physical, emotional, mental and social well-being in relation to sexuality. A positive and respectful approach to sexuality and sexual relationships, and possibilities of having pleasurable and safe sexual experiences free of discrimination, force and violence are necessary for sexual health [2]. Unsafe sex is estimated by the World Health Organization (WHO) to be the second most important global risk factor for health. Adolescents and young people are an especially vulnerable group concerning sexual health [1]. In a Swedish study of sexual behavior [3] on young people (age 15 - 29), the mean age for sexual debut was 16 yrs., approximately 70 percent of all sexual encounters were unprotected and the respondents reported that their latest sexual encounter was with someone they knew previously. The majority were sober at the latest sexual encounter.

Sexual risk behavior is a health determinant often linked to other risk behaviors such as alcohol consumption, use of drugs and substance abuse [1]. Sexual risk behavior among young people can be described as inconsequent usage of condoms, inconsequent use of other contraceptive methods, having multiple sexual partners and the use of drugs or alcohol before or while having sexual activity [4]. Sexual risk-taking can also include the risk of becoming or to make someone pregnant without willing it, and the risk of being infected by a sexually transmitted disease [5]. The incidence for chlamydia, the most common sexually transmitted disease in Sweden for 2013, was 372 cases per 100,000. Chlamydia has increased the last 15 years for both men and women. Of all the reported cases, 85\% were in the age group 15 - 29 [6]. The prevalence of chlamydia in EU/EEA member states is consistent with other high income countries, of sexually experienced young people age 25 and younger [7].

Attitudes, norms, and self-efficacy related to sexual behavior in young people could result in sexual risk-taking and may cause negative consequences for their sexual health [8]. Self-esteem has been seen by public health professionals and educators in sexuality over the years as a protective factor against various risk behaviors including sexual risk behavior [9]. There are different definitions of self-esteem. Rosenberg [10] defines self-esteem as a positive or negative attitude toward a particular object, the self. High self-esteem reflects the feeling that one is "good enough". Low self-esteem reflects on self-rejection, self-dissatisfaction, and self-contempt [10]. Studies have shown higher self-esteem in males than in females [8] [11]-[14].

Johnson [15] divides self-esteem into basic self-esteem and earning self-esteem. Basic self-esteem is based on essential elements of self-esteem where self-esteem refers to the affective-experiential perception of oneself. The degree of worth, value and love that the individual may hold for himself as a human being in the world can be used to define self-esteem. This love of oneself should include an individual's acceptance of his own basic needs, emotions and instincts such as love, sexuality and aggression. Earning self-esteem is related to an individual's need to earn self-esteem conditionally by being appreciated, competent, hard-working and responsible. This can also include the need to be in control of and exert influence over other people and situations [15]. There have been some studies conducted on sexual risk behavior in adolescence and self-esteem with varying results [16]-[18], but none using Johnson's constructs of basic self-esteem and earned self-esteem. In a review [18] on the relation between self-esteem and adolescents' sexual behaviors, attitudes, and intentions to engage in sexual risk behavior, research conducted previously has not resulted in a consensus on whether or not there are positive or negative associations.

A wider range in age of participants is more often included in studies on sexual behavior [3] [19] [20] while studies that focus on high school students are less prevalent. While many studies have been conducted in urban areas, there appears to be a lack of studies conducted on adolescents outside urban areas to see whether and how they differ from young people living in an urban environment [21] [22]. Further, knowledge of self-esteem, psychosocial factors affecting sexual risk behavior and how these differ between the genders may be of importance in planning measures to prevent sexual risk behavior and promote sexual health in young people. This indicates a further need for studies on young people in late adolescence as well as studies conducted in a rural environment.

\section{Aim}

The aim of the study was to describe high school students' sexual behavior and self-esteem, along with investigating the relationship of attitudes, norms, self-efficacy, and self-esteem with sexual risk behavior. Another aim 
was to describe and compare gender differences in self-esteem and sexual risk behavior in high school students in a rural context.

\section{Method}

\subsection{Design}

The study had a cross-sectional design using questionnaires for collecting data.

\subsection{Participants}

The participants were recruited using a systematic random sampling from a population of high school students from two high schools in a rural community in central Sweden. All together there were approximately 1,230 students enrolled in the high schools. A power calculation was conducted to determine the sample size needed for the study. For a reliability of 80 percent power and significance levels of 0.05 or lower at least 130 students were needed. The students were mainly from the community but a number of students also came from neighboring communities. To be eligible for the study participants were to be 16 to 18 years of age. Class lists were used for the selection where every third student was chosen, amounting to 363 students being chosen. After two reminders the response rate was 38\% $(n=139)$. The participants in the study were comprised of more females $57 \%(n=79)$ than males $43 \%(n=60)$. The total mean age was $17.01($ SD 0.86$)$ of which $35 \%(n=48)$ were 16 years of age, $28 \%(n=49)$ were 17 years of age, and $37 \%(n=51)$ were 18 years of age. The respondents that did not reply consisted of $61 \%(n=137)$ males and $39 \%(n=87)$ females. There were no significant differences concerning age groups in those that replied and those that did not reply.

\subsection{Data Collection}

Recruitment letters and questionnaires were distributed through class teachers for each respective class. The filled in questionnaires were left in a designated box at the school nurse's office. The principals of the high schools consented to the study.

\subsection{Measures}

In the present study three measures were used to assess self-esteem and variables affecting sexual risk behavior; the shortened versions of the Basic Self-Esteem Scale and Earning Self-Esteem Scale [23], and The Sexual Risk Behavior Beliefs and Self-Efficacy Scales (SRBBS) [24]. An additional six questions were included to assess sexual behavior. From an analysis of previous studies the chosen questions were: Have you ever had sexual intercourse? Have you ever had a venereal disease? Did you use a condom at your latest sexual intercourse? One question was on a scale ranging from $1=0$ to $4=$ three or more; How many sex partners have you had the last 12 months? Two questions are on a scale ranging from $1=$ always to 5 = never; How often have you used a condom the last three months? How often have you used alcohol during sexual intercourse the last three months? Demographic variables included age and gender.

The Basic Self-Esteem Scale [23] was developed to measure the degree of basic self-esteem which is given a subject more or less unconditionally. The original Basic Self-Esteem Scale consists of 42 items. The shortened version of the scale [23] which consists of 13 items from the original scale was used in this study. It has two factors of which the first (6 items) contained items relating to emotional warmth and openness (e.g. "I can freely express what I feel”). The second factor (7 items) contained items relating to self-assertiveness (e.g. "I find it easy to say no to other's demands”). The scale ranges from $1=$ strongly disagree to $5=$ strongly agree. High scores on The Basic Self-esteem scale indicate high levels of basic self-esteem while low scores indicate low levels of basic self-esteem. In previously studies the scale has Crohnbach's alpha coefficients ranging from 0.79 - 0.88 in different subsamples [25] [26]. In the present study the Cronbach's alfa was 0.83.

The Earning Self-Esteem Scale [23] consists of 37 items which measures a need to live up to certain standards in order to earn or maintain self-esteem based on competence or others' approval. The shortened version of the scale [23] which was used in this study consists of 13 items from the original scale. It has two factors. The first factor (7 items) containing items reflecting conditionally acquired self-worth (e.g. "When people like me my self-esteem is strengthened quite a lot”). The second factor (6 items) containing items reflecting high standards 
of accomplishment (e.g. "I think it’s important to succeed if I dedicate myself to something”). The scale ranges from $1=$ strongly disagree to $5=$ strongly agree. High scores on The Earning Self-esteem Scale indicate high levels of earning self-esteem while low scores indicate low levels of earning self-esteem. Cronbach's alfa coefficients in a previous study ranged from 0.79 - 0.80 [25]. In the present study the Cronbach's alfa was 0.52. According to Bowling [27] Crohnbach's alfa over 0.50 are accepted as adequate for internal consistency reliability.

The Sexual Risk Behavior Beliefs and Self-Efficacy Scales (SRBBS) which were used in this study consist of 22 variables, and were developed to measure important psychosocial variables affecting sexual risk-taking and protective behavior and are mainly used with high school students aged 14 to 18 [24]. The variables are based on three theories on behavior which can be used to predict risk-taking behavior; the Theory of Reasoned Action, the Social Cognitive Theory and the Health Belief Model [24]. The SRBBS have three scales which relate to sexual risk-taking behavior; attitudes about sexual intercourse (ASI), norms about sexual intercourse (NSI), and self-efficacy in refusing sex (SER). Five scales are related to protective behavior; attitudes about condom use (ACU), norms about condom use (NCU), self-efficacy in communication about condoms (SECM), self-efficacy in using and buying condoms (SECU), and barriers to condom use (BCU). The responses in subscales ASI, SCU, NSI, SECU are 1 = Definitely no, 2 = Probably no, 3 = Probably yes, $4=$ Definitely yes. In subscales SER, SECM, SECU the responses are $1=$ Not sure at all, $2=$ Kind of sure, $3=$ Totally sure and in subscale BCU the responses are 1 = I strongly disagree, 2 = I kind of disagree, $3=$ I kind of agree, 4 = I strongly agree. Higher values for seven of the eight scales reflect greater intention not to engage in sexual risk behavior. Higher scores for the eighth's scale (BCU) are related to lesser sexual risk behavior. Cronbach's alpha coefficients in the SRBBS showed good reliability, with scores ranging from 0.61 - 0.87 in the study of Basen-Engquist et al. [24]. The scales were used for correlations in this study. However in the present study Cronbach's alpha coefficients ranged from $0.37-0.88$, of which two scales had values less than 0.5 ; ASI 0.37 and NSI 0.42 . Translation of the SRBBS from English into Swedish was conducted using a method presented by Bullinger et al. [28].

\subsection{Data Analysis}

Data were analyzed using SPSS version 17 and 18. Descriptive statistics were used to measure means and standard deviation. The variables used for the analysis were basic self-esteem, earned self-esteem and variables affecting sexual risk behavior. Statistical tests used to determine significance levels between genders were the Mann-Whitney U- test and Person's Chi-square test. For analysis of correlations between self-esteem and sexual risk behavior factor Pearson's product-moment correlations was used. The level of statistical significance was set at $\mathrm{P} \leq 0.05$ (two-tailed probability). Cronbach's alfa coefficients were calculated to measure the internal consistency of the used scales.

\subsection{Ethical Considerations-Ethical Issues and Approvals}

According to Swedish law (2003:460) [29] young people who have turned 15 years of age but not yet 18 years may give informed consent to take part in a research study under the conditions that he or she is aware of what it involves and has received sufficient information. The participants in the study received written information and they could at any time refuse to take part in the study. The study was granted ethical approval by the Committee on Research Ethics, Karlstad University, Sweden (dnr C 2009/254).

\section{Results}

\subsection{The Students' Sexual Behavior}

The majority of the students $96 \%(n=133)$ stated that they were heterosexual; two bisexual, and one homosexual. Three students chose not to state their sexual orientation. Thirty percent $(n=42)$ of the students had never experienced sexual intercourse, 68\% $(n=94)$ had experienced sexual intercourse (missing $=3)$. There were no significant differences between the age groups or gender in regards to experience of sexual intercourse, nor among those with no experience of sexual intercourse. Of those who had experienced sexual intercourse, the rate was higher among female students $60 \%(n=56)$ than male students $40 \%(n=38)$ (not significant). In this group, eight students (seven female and one male) reported having a venereal disease.

A description of sexual behavior by age and gender among students $(n=94)$ with experience of sexual intercourse are shown in Table 1. 
Table 1. Sexual behavior and total by gender of those who had experience of sex among high school students.

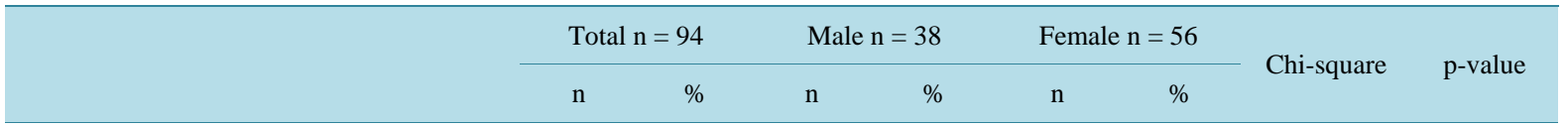

Ever had sex (Age)

16
17

$\begin{array}{llllllll}32 & 34 & 15 & 40 & 17 & 30 & & \\ 29 & 31 & 13 & 34 & 16 & 29 & & \\ 33 & 35 & 10 & 26 & 23 & 41 & 2.190 & 0.335\end{array}$

Used a condom during the last three months

Always
Often
Half of the time
Seldom
Never

$\begin{array}{lccccccc}16 & 17 & 7 & 18 & 9 & 16 & & \\ 10 & 10 & 3 & 7 & 7 & 12 & & \\ 4 & 4 & 2 & 5 & 2 & 3 & & \\ 17 & 18 & 7 & 18 & 10 & 18 & & \\ 46 & 49 & 19 & 50 & 27 & 49 & 0.686 & 0.953\end{array}$

Number of sex partners the last 12 months

0
1
2
3 or more

Used alcohol during sex

Never

Half of the time

Often

Always

$\begin{array}{cccccc}7 & 8 & 5 & 13 & 2 & 4 \\ 43 & 46 & 17 & 45 & 26 & 47 \\ 23 & 25 & 9 & 24 & 14 & 25 \\ 20 & 21 & 7 & 18 & 13 & 24\end{array}$

4

47

25

3.051

0.384

Table 1 showed that half of the students never used a condom while nearly one fifth stated that they always used a condom. As for condom use during the latest sexual intercourse, $61 \%(n=57)$ of the students stated that they did not use a condom (not shown in table). Nearly half of the students reported that they had at most one sex partner during the last twelve months. Approximately one fifth of students stated that they had three or more sex partners during this period.

A majority of students replied that they never or seldom $(84 \%, \mathrm{n}=78)$ used alcohol in connection with sex. There was no significant difference in use of alcohol in connection with sex between those students with three or more sex partners and those with two or less sex partners (not shown in table). There were no significant differences between genders in the variables measured.

\subsection{Factors Affecting Sexual Risk Behavior}

The psychosocial factors attitudes, norms and self-efficacy are illustrated in Table 2. High scores for attitudes, norms, and self-efficacy reflect greater intention not to engage in sexual risk behavior, while low scores reflect a greater intention to engage in sexual risk behavior such as not abstaining from sexual intercourse or not using condoms. Higher scores for barriers for condom use indicate low perceived barriers for condom use.

The results in Table 2 showed that the students reported being supportive of condom use and having good self-efficacy in using condoms, while their attitudes and norms were not focused on abstaining from sex. Females showed significantly higher scores on scales showing attitudes, norms and self-efficacy more supportive 
Table 2. Attitudes, norms, and self-efficacy among high school students.

\begin{tabular}{|c|c|c|c|c|c|c|c|c|}
\hline & \multicolumn{2}{|c|}{ Total $n=139$} & \multicolumn{2}{|c|}{ Males $n=60$} & \multicolumn{2}{|c|}{ Females n = 79} & \multicolumn{2}{|c|}{ Mann Whitney U-test } \\
\hline & M & SD & M & SD & M & $\mathrm{SD}$ & z-value & p-value \\
\hline Attitudes about sexual intercourse ${ }^{1}$ & 1.55 & 0.52 & 1.46 & 0.53 & 1.62 & 0.51 & -2.197 & 0.028 \\
\hline Attitudes about condom use ${ }^{2}$ & 2.89 & 0.80 & 2.92 & 0.79 & 2.87 & 0.82 & -0.357 & 0.721 \\
\hline Norms about sexual intercourse ${ }^{3}$ & 1.46 & 0.46 & 1.49 & 0.51 & 1.44 & 0.43 & -0.322 & 0.747 \\
\hline Norms about condom use ${ }^{1}$ & 2.58 & 0.74 & 2.78 & 0.75 & 2.44 & 0.70 & -2.794 & 0.005 \\
\hline Self-efficacy in refusing sex ${ }^{4}$ & 2.28 & 0.69 & 1.82 & 0.66 & 2.64 & 0.48 & -6.891 & 0.000 \\
\hline Self-efficacy in communication about condoms ${ }^{4}$ & 2.69 & 0.39 & 2.71 & 0.39 & 2.67 & 0.38 & -0.700 & 0.484 \\
\hline Self-efficacy in using and buying condoms ${ }^{4}$ & 2.47 & 0.52 & 2.59 & 0.48 & 2.38 & 0.54 & -2.500 & 0.012 \\
\hline Barriers to condom use ${ }^{5}$ & 2.00 & 0.76 & 1.88 & 0.67 & 2.09 & 0.82 & -1.434 & 0.151 \\
\hline
\end{tabular}

Note: Response format Attitudes and norms: 4 = Definitely yes, 3 = Probably yes, 2 = Probably no, 1 = Definitely no; Self-efficacy: 3 = Totally sure, 2 = Kind of sure, 1 = Not sure at all; Barriers to condom use: 4 = I strongly agree, 3 = I kind of agree, $2=$ I kind of disagree, 1 = I strongly disagree;

${ }^{1}$ High scores indicate attitudes supporting abstinence; ${ }^{2}$ High scores are supportive of condom use; ${ }^{3}$ High scores indicate norms supporting abstinence;

${ }^{4}$ High scores indicate high self-efficacy; ${ }^{5}$ High scores indicate low perceived barriers.

to refusing sex. Males had significantly higher scores than females on the scales indicating positive norms about condom use and good self-efficacy in buying and using condoms. Four of the scales could not prove significant differences between males and females.

\subsection{Self-Esteem}

The students in this study reported having high levels of self-esteem (values of 3.0 or higher) as seen in Figure 1.

Scores on the scales for self-esteem are shown in Table 3.

Students showed high scores for both basic self-esteem and earned self-esteem. Male students had significantly higher scores on basic self-esteem than female students while female students had significantly higher scores on earned self-esteem than male students.

\subsection{Correlations between Self-Esteem and Factors Associated with Sexual Risk Behavior}

The results of the analysis on the correlations between self-esteem and psychosocial factors associated with sexual risk behavior are shown in Table 4.

The analysis showed a significant positive correlation for Basic self-esteem and self-efficacy for using and buying condoms which means that higher basic self-esteem is associated with a greater self-efficacy for buying and using condoms. Basic self-esteem and barriers to condom use showed a negative correlation which means that higher basic self-esteem correlated with less perceived barriers to buying and using condom (Table 4). Earned self-esteem and condom use the last three months among the students who had experienced intercourse showed a negative correlation which suggests that higher earned self-esteem was associated with reduced use of condoms during the time period, $r=-0.27$ and $\mathrm{p}=0.009$ (not in table).

\subsection{Correlations between Sexual Behavior and Factors Associated with Sexual Risk Behavior}

The correlations between sexual behavior and psychosocial factors associated with sexual risk behavior are shown in Table 5.

A significant negative correlation was seen between attitudes about sexual intercourse and condom use the last three months which suggests that a greater intention not to engage in sex associated with less use of condoms. Attitudes about condom use showed a significant negative correlation with the use of condoms the last three months and also with the use of a condom at the latest intercourse (Table 5). 


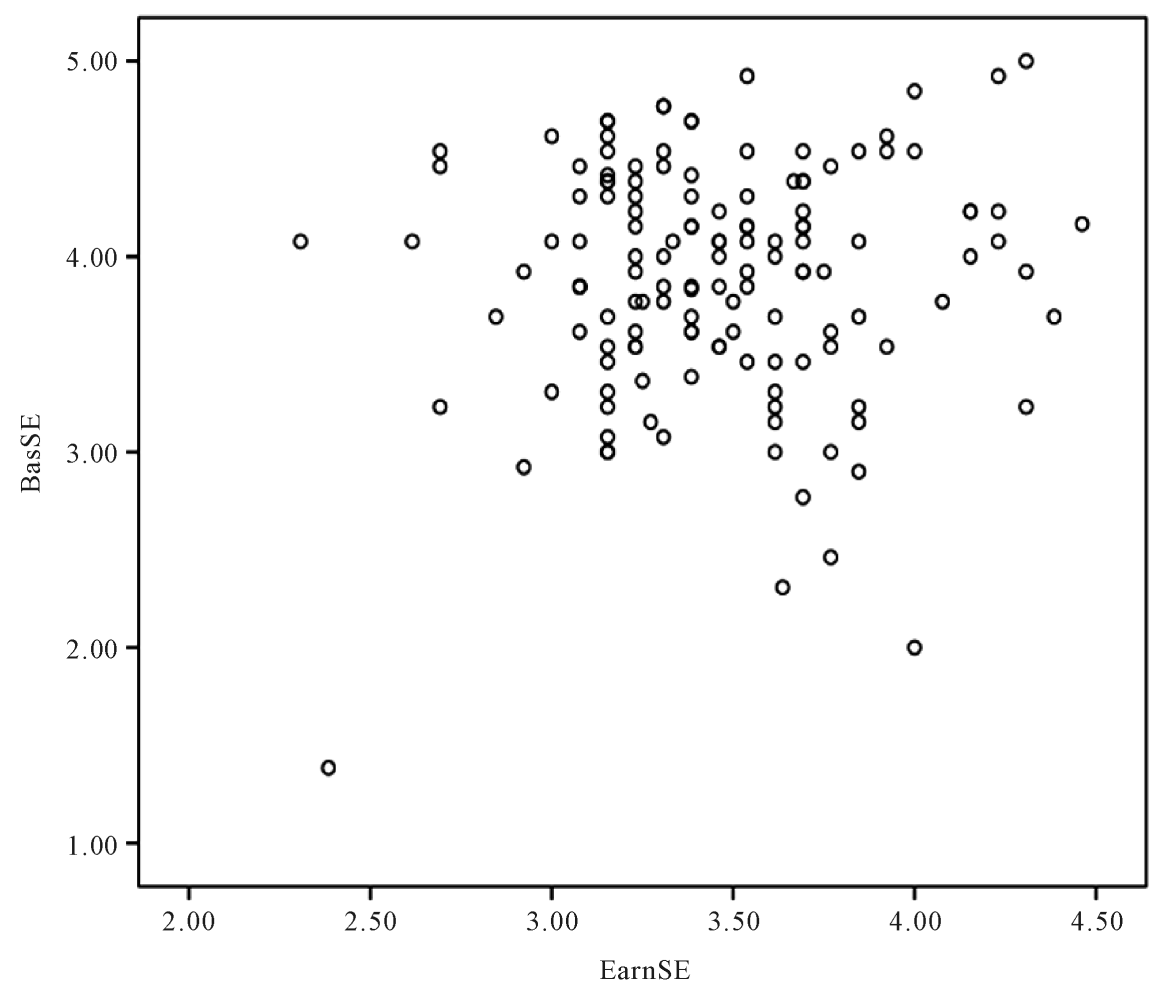

Figure 1. Scatter diagram for the spread of the variables basic self-esteem and earned self-esteem.

Table 3. Basic self-esteem and earned self-esteem total and by gender among high school students.

\begin{tabular}{cccccccccc}
\hline & \multicolumn{2}{c}{ Total $\mathrm{n}=139$} & \multicolumn{2}{c}{ Males $\mathrm{n}=60$} & \multicolumn{2}{c}{ Females $\mathrm{n}=79$} & \multicolumn{2}{c}{ Mann Whitney U-Test } \\
\cline { 2 - 10 } & $\mathrm{M}$ & $\mathrm{SD}$ & $\mathrm{M}$ & $\mathrm{SD}$ & $\mathrm{M}$ & $\mathrm{SD}$ & z-value & $\mathrm{p}$-value \\
\hline Basic self-esteem & 3.90 & 0.60 & 4.07 & 0.59 & 3.76 & 0.57 & -3.324 & 0.001 \\
Earned self-esteem & 3.46 & 0.40 & 3.33 & 0.41 & 3.56 & 0.36 & -3.318 & 0.001 \\
\hline
\end{tabular}

Note: Response format: strongly disagree (1) to strongly agree (5).

Table 4. Pearson correlations between self-esteem and factors associated with sexual risk behavior.

\begin{tabular}{ccc}
\hline & Basic self-esteem & Earned self-esteem \\
\hline Attitudes to sexual intercourse & -0.11 & $0.22^{* *}$ \\
Attitudes about condom use & -0.07 & 0.15 \\
Norms about sexual intercourse & -0.07 & 0.07 \\
Norms about condom use & 0.06 & 0.02 \\
Self-efficacy for refusing sexual intercourse & -0.11 & $0.17^{*}$ \\
Self-efficacy for communication about condom use & 0.10 & 0.04 \\
Self-efficacy for buying and using condoms & $0.26^{* *}$ & -0.14 \\
Barriers to condom use & $-0.31^{* *}$ & 0.16 \\
\hline
\end{tabular}

${ }^{*}$ Correlation is significant at the 0.05 level (2-tailed); ${ }^{* *}$ Correlation is significant at the 0.01 level (2-tailed). 
Table 5. Pearson correlations between sexual behavior and factors associated with sexual risk behavior.

\begin{tabular}{|c|c|c|c|c|c|}
\hline & $\begin{array}{l}\text { Have experienced a } \\
\text { sexually transmitted } \\
\text { infection }\end{array}$ & $\begin{array}{l}\text { Condom use } \\
\text { the past three } \\
\text { months }\end{array}$ & $\begin{array}{l}\text { Number of sex } \\
\text { partners the past } \\
12 \text { months }\end{array}$ & $\begin{array}{l}\text { Use of condom } \\
\text { at latest sexual } \\
\text { intercourse }\end{array}$ & $\begin{array}{l}\text { Use of alcohol } \\
\text { in connection } \\
\text { with sex }\end{array}$ \\
\hline Attitudes to sexual intercourse & -0.06 & $-0.34^{* *}$ & -0.00 & $-0.23^{*}$ & -0.17 \\
\hline Attitudes about condom use & $-0.31^{* *}$ & $-0.50^{* *}$ & $-0.25^{*}$ & $-0.51^{* *}$ & -0.20 \\
\hline Norms about sexual intercourse & 0.01 & $-0.26^{*}$ & 0.05 & -0.12 & $-0.21^{*}$ \\
\hline Norms about condom use & $-0.23^{*}$ & $-0.40^{* *}$ & -0.18 & $-0.45^{* *}$ & -0.18 \\
\hline $\begin{array}{l}\text { Self-efficacy for refusing } \\
\text { sexual intercourse }\end{array}$ & 0.09 & -0.14 & -0.10 & -0.08 & -0.12 \\
\hline $\begin{array}{l}\text { Self-efficacy for communication } \\
\text { about condom use }\end{array}$ & 0.09 & $-0.24^{*}$ & -0.15 & $-0.25^{*}$ & -0.14 \\
\hline $\begin{array}{l}\text { Self-efficacy for buying } \\
\text { and using condoms }\end{array}$ & 0.78 & -0.09 & -0.03 & 0.00 & -0.10 \\
\hline Barriers to condom use & -0.14 & -0.04 & -0.11 & 0.04 & -0.07 \\
\hline
\end{tabular}

${ }^{*}$ Correlation is significant at the 0.05 level (2-tailed). ${ }^{* *}$ Correlation is significant at the 0.01 level (2-tailed).

Norms about condom use showed also significant negative correlations to condom use the last three months and used condom at the latest intercourse. There were no associations between norms positive about condom use and more consistent use of condoms the last three months and less use of condoms at the latest intercourse.

\section{Discussion}

The results of this study show a wide range in sexual behavior, from one third of the students reporting no experience of sexual intercourse to one fifth who had experience of several sex partners. The students who reported having three or more sex partners in the last twelve months also reported less consistent use of condoms than students with fewer sex partners during that period.

The students' attitudes and norms about sexual intercourse indicate an accepting attitude towards sex. The students' statements on their friends' attitudes and norms coincided with their own attitudes and norms. According to the SRBBS, high scores on the subscales for attitudes and norms for intercourse indicate attitudes and norms supportive of abstaining from sex while low scores predict a risk for engaging in sex [24]. Despite positive attitudes and norms for sexual intercourse in this study students had few sex partners, contrary to expected outcome in accordance to the SRBBS. Positive attitudes and norms about sexual intercourse do not necessarily imply that there will be an increase in the number of partners. The students' positive attitudes and norms for intercourse and the low number of sexual partners suggest that other factors may be more important for making the decision to abstain or engage in intercourse such as the Ideology of love in which sex belongs in a loving relationship and more effective contraceptives [30].

The psychosocial factors; attitudes, norms and self-efficacy used in the SRBBS scales are meant to predict sexual risk behavior, yet in the current study the psychosocial factors did not always coincide with the sexual risk behavior. Students' attitudes towards condom use, norms regarding condom use, self-efficacy in communicating about condom usage, and self-efficacy in buying and using condoms are all independently associated with lesser sexual risk behavior according to the SRBBS scales. Yet approximately half of the respondents expose themselves to risks by not using condoms. Students had good self-efficacy in using condoms. Male students reported greater condom use self-efficacy than female students which corresponds with prior research [31]. There was although a discrepancy between high self-efficacy in using condoms and inconsistent condom use. Of those students in this study who had experience of sex, nearly half of the students only had at most one sex partner in the last twelve months which could possibly be due to being in a relationship. Tikkanen et al. [3] found that unprotected sex occurred more often when the sex partner was a boyfriend or girlfriend. Other reasons for not using condoms may result from the lack of perceived health risk, other contraceptive use, or inconvenience [32]. More recent studies show other factors of importance for condom use such as difficulties in communicating with 
a partner about condom use [33] [34] distinguishing between temporary sexual contacts and relationships [34]. Studies also report other important factors such as that condoms are less pleasurable, difficult to use and embarrassing to have sex with a condom [35], judging risk after appearance [36] [37], and use of alcohol in connection with sexual activity [34] [36].

The students in this study reported having high levels of both basic and earned self-esteem. The constructs of basic and earned self-esteem have not been previously studied in this age group. The use of Johnson's constructs of basic and earned self-esteem is of great value in examining gender differences in self-esteem among adolescents. The results imply that female students to a greater extent gain their self-esteem by being competent and through appreciation than the male students. Although self-esteem can be measured in different ways, the results are supported by other studies showing higher self-esteem in males regardless to which scale is used [3] [11][14]. Good self-esteem in young people is also supported by other studies [13] [14] [38]. However in a review by Goodson et al. [18], no associations were found between self-esteem and sexual behavior, attitudes, or intentions, but they go on to discuss that one reason for the results may be due to be the lack of conceptual or measurement specificity [18]. It could be of interest to further examine Johnson's constructs of self-esteem in young people related to sexual behavior. In this study there were too few students reporting low self-esteem to be able to investigate the relationships.

This study was conducted in a rural community in central Sweden. Studies on factors influencing sexual behavior have mainly been conducted on older adolescents attending high schools in urban areas [39]. In Tikkanen et al. [3] less than one fifth of the respondents lived in a smaller town or rural community while the majority lived in one of the three major cities in Sweden. They found no significant demographic differences in early sexual debut. The mean age for sexual debut for females was 15.9 and for males 16.4 [3]. In the current study about one third of the students age 16 reported not having experienced sex.

\subsection{Methodological Considerations and Limitations}

In this study there are some methodological considerations to be acknowledged. Strengths for the study include the use of scales, which were tested for validity and reliability showing good internal consistency. Cronbach's alpha coefficients were low for the scales Attitudes about sexual intercourse and Norms about sexual intercourse. The low values on those scales could be the result of the cultural differences between Sweden and the US on how young people view sexuality. However it could also be contributed to the scales being comprised of only two items each. According to Streiner and Norman [40] interpreting high Crohnbach's alpha coefficients as reflecting on high internal consistency may be deceiving because it is not only dependent on the magnitude of the correlations among items, but is also dependent on the number of items in the scale [40].

Some caution should although be taken in interpreting the results of the SRBBS, since they were developed in the US and may not accurately predict sexual risk behavior in other cultures. Through sex education in schools in Sweden, young people are encouraged to have an open and positive view on sexuality and sexuality [41]. Harden [42] found that a sex-positive framework, which considers adolescent sexual activities as developmentally normative and potentially health, does not cause worse psychological functioning compared to a riskperspective approach viewing abstinence from sexual activity as the ideal behavioral outcome for adolescents. In the US adolescent sexual activity is commonly considered to be a risk behavior and abstinence is seen as the healthiest behavioral outcome for adolescents [42].

Language validation from English to Swedish of the SRBBS was performed by use of Bullinger et al.'s [28] method for the translation of health status questionnaires. To avoid bias and ensure external validity in the study the sample selection was obtained by way of a systematic sample using class lists. Strengths for the study are also the random sample of participants.

A limitation in this study was the low response rate. However an analysis showed that there were no significant differences concerning age groups in those that replied and those that did not reply, but here was a significant gender difference in the response rate with more female participants than male. Questionnaires consisting of many questions along with questions of a more sensitive nature may also have affected the response rate. Fenton, Johnson, McManus, and Erens [43] state that in postal surveys studying sexual behavior it is not uncommon with non-return rates of $40 \%$. Participation bias, i.e. error caused by systematic differences in the characteristics such as gender, age or sexual behavior of those who chose to reply compared to those who abstained from replying has been discussed, but studies show little differences in sexual behavior of early responders 
willing to take part in surveys on sexual behavior and late responders who were difficult to recruit [43]. Compared to interviewing, self-completion questionnaires may reduce the need to disclose sensitive information and thus result in greater validity [43].

\subsection{Conclusion and Implication for Further Research}

The high school students had several positive sexual behaviors including a small number of sex partners, despite positive attitudes and norms for sexual intercourse, and seldom use of alcohol during sex. On the other hand many put themselves at risk by inconsistent use of condoms. The students showed positive attitudes and norms for condom usage and reported good self-efficacy in condom use, which should predict a more consistent use of condoms than the actual results showed, which suggests that other factors may be of greater importance for using condoms. The scales measuring self-esteem, based on the constructs of basic self-esteem and earned selfesteem, have not been used on adolescents previously and can therefore contribute to new knowledge on selfesteem in adolescence. Self-esteem was high for the students but did not seem to be a factor of importance in relation to sexual behavior. Male students had higher basic self-esteem while female students had higher earned self-esteem which means that female students had a greater need than male students to gain self-esteem by competence and approval.

This study suggests that it is important that nurses working with young people, such as school nurses and midwifes working in youth clinics, are aware about the role of self-esteem, attitudes, norms, and self-efficacy is of importance when discussing sexual behavior with young people. An important goal of nursing is to promote healthy outcomes for individuals in transitional stages, such as the development from adolescence to adulthood [44]. Healthy outcomes can be seen as subjective well-being, mastering roles, and good relationships, which are all of importance for sexual health. School nurses and midwifes in youth clinics are in a key position to discuss sexual health issues with adolescents. The focus of the discussion should preferably include the actual use of condoms. This can also be addressed by role playing for example during sex-education lessons in which nurses can participate. Further research on adolescents' perspectives and views on sexuality and sexual behavior is needed to develop further strategies for promoting sexual health and preventing negative outcomes of sexual risk behavior. Research investigating reasons for not using condoms is another area of importance in future research. Also further research on the role of gender differences in Earned self-esteem and its part in sexual risk taking may be of value.

\section{References}

[1] EU Public Health Programme Project (2007) Global Report on the Health Status in the European Union (EUGLOREH). The Status of Health in the European Union: Towards a Healthier Europe. http://www.intratext.com/ixt/_EXT-rep/_P5P.HTM.

[2] World Health Organization (WHO) (2006) Sexual and Reproductive Health Defining Sexual Health. http://www.who.int/reproductivehealth/topics/sexual_health/sh_definitions/en/index.html

[3] Tikkanen, R.H., Abelsson, J. and Forsberg, M. (2011) UngKAB09 Kunskap, Attityder Och Sexuella Handlingar Bland Unga (UngKAB09 Knowledge, Attitudes and Sexual Actsamong the Young). University of Gothenburg, Gothenburg, Department of Social Work, Skriftserien, 1.

[4] Kotchick, B.A., Shaffer, A., Forehand, R. and Miller, K.S. (2001) Adolescent Sexual Risk Behaviour: A Multi-System Perspective. Clinical Psychology Review, 21, 493-519. http://dx.doi.org/10.1016/S0272-7358(99)00070-7

[5] Forsberg, M. (2006) Adolescent Sexuality in Sweden. Swedish National Institute of Public Health, Stockholm, 18.

[6] Public Health Agency in Sweden (2013) Klamydiainfektion. http://www.folkhalsomyndigheten.se/amnesomraden/statistik-och-undersokningar/sjukdomsstatistik/klamydiainfektion ? $\mathrm{t}=$ com\#statistics-nav

[7] European Centre for Disease Prevention and Control (2014) Chlamydia Control in Europe: Literature Review. http://www.ecdc.europa.eu/en/publications/_layouts/forms/Publication_DispForm.aspx?List=4f55ad51-4aed-4d32-b96 0-af70113dbb90\&ID=1021

[8] Swedish National Institute of Public Health (2011) Sexuality and Reproductive Health. Swedish National Institute of Public Health, Stockholm, 02.

[9] Goodson, P., Buhi, E.R. and Dunsmore, S.C. (2006) Self-Esteem and Adolescent Sexual Behaviors, Attitudes, and Intentions: A Systematic Review. Journal of Adolescent Health, 38, 310-319. 
http://dx.doi.org/10.1016/j.jadohealth.2005.05.026

[10] Rosenberg, M. (1965) Society and the Adolescent Self-Image. Princeton University Press, Princeton.

[11] Dusek, J.B. and McIntyre, J.G. (2003) Self-Concept and Self-Esteem Development. In: Adams, G.R. and Berzonsky, M.D., Eds., Blackwell Handbook of Adolescence, Blackwell Publishing Ltd., Malden, 290-309.

[12] Birndorf, S., Ryan, S., Auinger, P. and Aten, M. (2005) High Self-Esteem among Adolescents: Longitudinal Trends, Sex Differences, and Protective Factors. Journal of Adolescent Health, 37, 194-201. http://dx.doi.org/10.1016/j.jadohealth.2004.08.012

[13] Harter, S. (2006) Developmental and Individual Difference Perspectives on Self-Esteem. In: Mroczek, D.K. and Little, T.D., Eds., Handbook of Personality Development, Lawrence Erbaum Associates, Inc., New Jersey, 311-334.

[14] Sharif, A. and Smrecki, M. (2008) Självkänslaochhälsa hos ungdomar, Betydelseavetnicitetochkön (Self-Esteem and Health among Young People, the Meaning of Ethnicity and Gender). Thesis, Mälardalen University Sweden, School of Sustainable Development of Society and Technology, Eskilstuna, Västerås.

[15] Johnson, M. (1997) On the Dynamics of Self-Esteem: Empirical Validation of Basic Self-Esteem and Earning SelfEsteem. Dissertation, Stockholm University, Department of Psychology, Stockholm.

[16] McGee, R. and Williams, S. (2000) Does Low Self-Esteem Predict Health Compromising Behaviors among Adolescents? Journal of Adolescence, 23, 569-582. http://dx.doi.org/10.1006/jado.2000.0344

[17] Wild, L.G., Flisher, A.J., Bhana, A. and Lombard, C. (2004) Associations among Adolescent Risk Behaviors and Self-Esteem in Sex Domains. Journal of Child Psychology and Psychiatry, 45, 1454-1467. http://dx.doi.org/10.1111/j.1469-7610.2004.00330.x

[18] Goodson, P., Buhi, E.R. and Dunsmore, S.C. (2006) Self-Esteem and Adolescent Sexual Behaviors, Attitudes, and Intentions: A Systematic Review. Journal of Adolescent Health, 38, 310-319. http://dx.doi.org/10.1016/j.jadohealth.2005.05.026

[19] Scott, M.E., Wildsmith, E., Welti, K., Ryan, S., Schelar, E. and Steward-Streng, N.R. (2011) Risky Adolescent Sexual Behaviors and Reproductive Health in Young Adulthood. Perspectives on Sexual and Reproductive Health, 43, 110118. http://dx.doi.org/10.1363/4311011

[20] Frost, J.J., Duberstein Lindberg, L. and Finer, L.B. (2012) Young Adults’ Contraceptive Knowledge, Norms and Attitudes: Associations with Risk of Unwanted Pregnancy. Perspectives on Sexual and Reproductive Health, 44, 107-116. http://dx.doi.org/10.1363/4410712

[21] Dake, J.A., Price, J.H., Ward, B.L. and Welch, P.J. (2011) Midwestern Rural Adolescents’ Oral Sex Experience. Journal of School Health, 81, 159-165. http://dx.doi.org/10.1111/j.1746-1561.2010.00575.X

[22] Stewart Fahs, P.S., Smith, B.E., Atav, A.S., Britten, M.X., Collings, M.S., Lake Morgan, L.C. and Spencer, G.A. (1999) Integrative Research Review of Risk Behaviors among Adolescents in Rural, Suburban, and Urban Areas. Journal of Adolescent Health, 24, 230-243. http://dx.doi.org/10.1016/S1054-139X(98)00123-2

[23] Forsman, L. and Johnson, M. (1996) Dimensionality and Validity of Two Scales Measuring Different Aspects of SelfEsteem. Scandinavian Journal of Psychology, 37, 1-15. http://dx.doi.org/10.1111/j.1467-9450.1996.tb00635.X

[24] Basen-Engquist, K., Mâsse, L.C., Coyle, D., Kirby, D., Parcel, G.S., Banspach, S. and Nodora, J. (1999) Validity of Scales Measuring the Psychosocial Determinants of HIV/STD-Related Risk Behaviour in Adolescents. Health Education Research Theory \& Practice, 14, 25-38. http://dx.doi.org/10.1093/her/14.1.25

[25] Johnson, M. and Blom, V. (2007) Development and Validation of Two Measures of Contingent Self-Esteem. Individual Differences Research, 5, 300-328.

[26] Johnson, M. (1998) Self-Esteem Stability: The Importance of Basic Self-Esteem and Competence Strivings for the Stability of Global Self-Esteem. European Journal of Personality, 12, 103-116.

http://dx.doi.org/10.1002/(SICI)1099-0984(199803/04)12:2<103::AID-PER310>3.0.CO;2-8

[27] Bowling, A. (2002) Research Methods in Health, Investigating Health and Health Services. 2nd Edition, Open University Press, Maidenhead.

[28] Bullinger, M., Alonso, J., Apolone, G., Leplège, A., Sullivan, M., Wood-Dauphinee, S., Gandek, B., Wagner, A., Aaronson, N., Bech, P., Fukuhara, S., Kaasa, S. and Ware, J.E. (1998) Translating Health Status Questionnaires and Evaluating Their Quality: The IQOLA Project Approach. Journal of Clinical Epidemiology, 51, 913-923. http://dx.doi.org/10.1016/S0895-4356(98)00082-1

[29] SFS (2003) Lag om etikprövning av forskning som avser människor (The Act Concerning the Ethical Review of Research Involving Humans). Justitiedepartementet, Stockholm. (In Swedish)

[30] Herlitz, C.A. and Forsberg, M. (2010) Sexual Behaviour and Risk Assessment in Different Age Cohorts in the General Population of Sweden (1989-2007). Scandinavian Journal of Public Health, 38, 32-39. http://dx.doi.org/10.1177/1403494809355072 
[31] Farmer, M.A. and Meston, C.M. (2006) Predictors of Condom Use Self-Efficacy in an Ethnically Diverse University Sample. Archives of Sexual Behavior, 35, 313-326. http://dx.doi.org/10.1007/s10508-006-9027-5

[32] Carter, J.A., McNair, L.D., Corbin, W.R. and Williams, M. (1999) Gender Differences Related to Heterosexual Condom Use: The Influence of Negotiation Styles. Journal of Sex \& Marital Therapy, 25, 217-225. http://dx.doi.org/10.1080/00926239908403996

[33] Ekstrand, M. (2008) Sexual Risk Taking-Perceptions of Contraceptive Use, Abortion, and Sexually Transmitted Infections among Adolescents in Sweden. Dissertation, Uppsala University, Faculty of Medicine, Uppsala.

[34] Hammarlund, K. (2009) Risky Encounters-Young People’s Experiences of Sexually Transmitted Infections and Sexual Risk Taking. Dissertation, Linnaeus University, School of Health and Caring Sciences, Växjö.

[35] Darj, E. and Bondestam, K. (2003) Ungdomars syn på kondomanvändning (Young People’s Views on Condomuse). Läkartidningen, 100, 3510-3512.

[36] Christianson, M. (2006) What's behind Sexual Risk Taking? Exploring the Experiences of Chlamydia-Positive, HIVPositive, and HIV-Tested Young Women and Men in Sweden. Dissertation, Umeå University, Department of Public Health and Clinical Medicine/Family Medicine, Umeå.

[37] Akers, A.Y., Gold, M.A., Coyne-Beasley, T. and Corbie-Smith, G. (2012) A Qualitative Study of Rural Black Adolescents' Perspectives on Primary STD Prevention Strategies. Perspectives on Sexual and Reproductive Health, 44, 92-99. http://dx.doi.org/10.1363/4409212

[38] Bjurling, M. (2006) Relationen mellan sexuell hälsa och bassjälvkänsla bland unga vuxna. Thesis, Mälardalen University Sweden, School of Sustainable Development of Society and Technology, Eskilstuna, Västerås.

[39] Rue, L., Carver, T. and Chia-Chun, L. (2011) Early and Risky Sexual Behavior in a Sample of Rural Adolescents. Issues in Comprehensive Pediatric Nursing, 34, 189-204. http://dx.doi.org/10.3109/01460862.2011.619861

[40] Streiner, D.L. and Norman, G.R. (1995) Health Measurement Scales, a Practical Guide to Their Development and Use. 2nd Edition, Oxford Medical Publications, Oxford University Press, Oxford.

[41] Wallin, A. (2012) En forskningsöversikt om undervisning i sex och samlevnad (A Research Rewiew on Sex Education). In: Wallin, A., Bengtsdotter Katz, V., Hermansson Adler, M., Katz, O., Lustig, F. and West, E., Eds., Undervisning $i$ sex och samlevnad: ett idématerial, Göteborgs Universitet, Gothenburg, 15-34. https://gupea.ub.gu.se/handle/2077/28879

[42] Harden, K.P. (2014) A Sex-Positive Framework for Research on Adolescent Sexuality. Perspectives on Psychological Science, 9, 445-469. http://dx.doi.org/10.1177/1745691614535934

[43] Fenton, K.A., Johnson, A.M., McManus, S. and Erens, B. (2001) Measuring Sexual Behaviours: Methodological Challenges in Survey Research. Sexually Transmitted Infections, 77, 84-92. http://dx.doi.org/10.1136/sti.77.2.84

[44] Meleis, A.I. (2010) Transitions Theory Middle-Range and Situation-Specific Theories in Nursing Research and Practice. Springer Publishing Company, New York. 
Scientific Research Publishing (SCIRP) is one of the largest Open Access journal publishers. It is currently publishing more than 200 open access, online, peer-reviewed journals covering a wide range of academic disciplines. SCIRP serves the worldwide academic communities and contributes to the progress and application of science with its publication.

Other selected journals from SCIRP are listed as below. Submit your manuscript to us via either submit@scirp.org or Online Submission Portal.
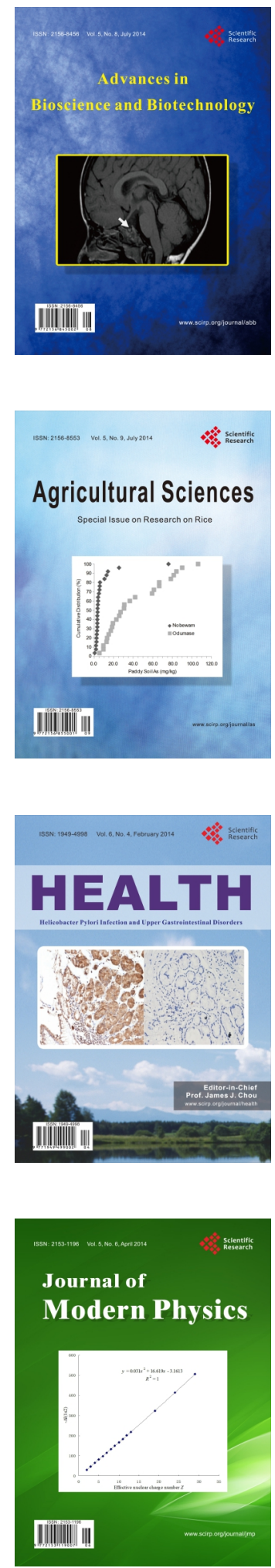
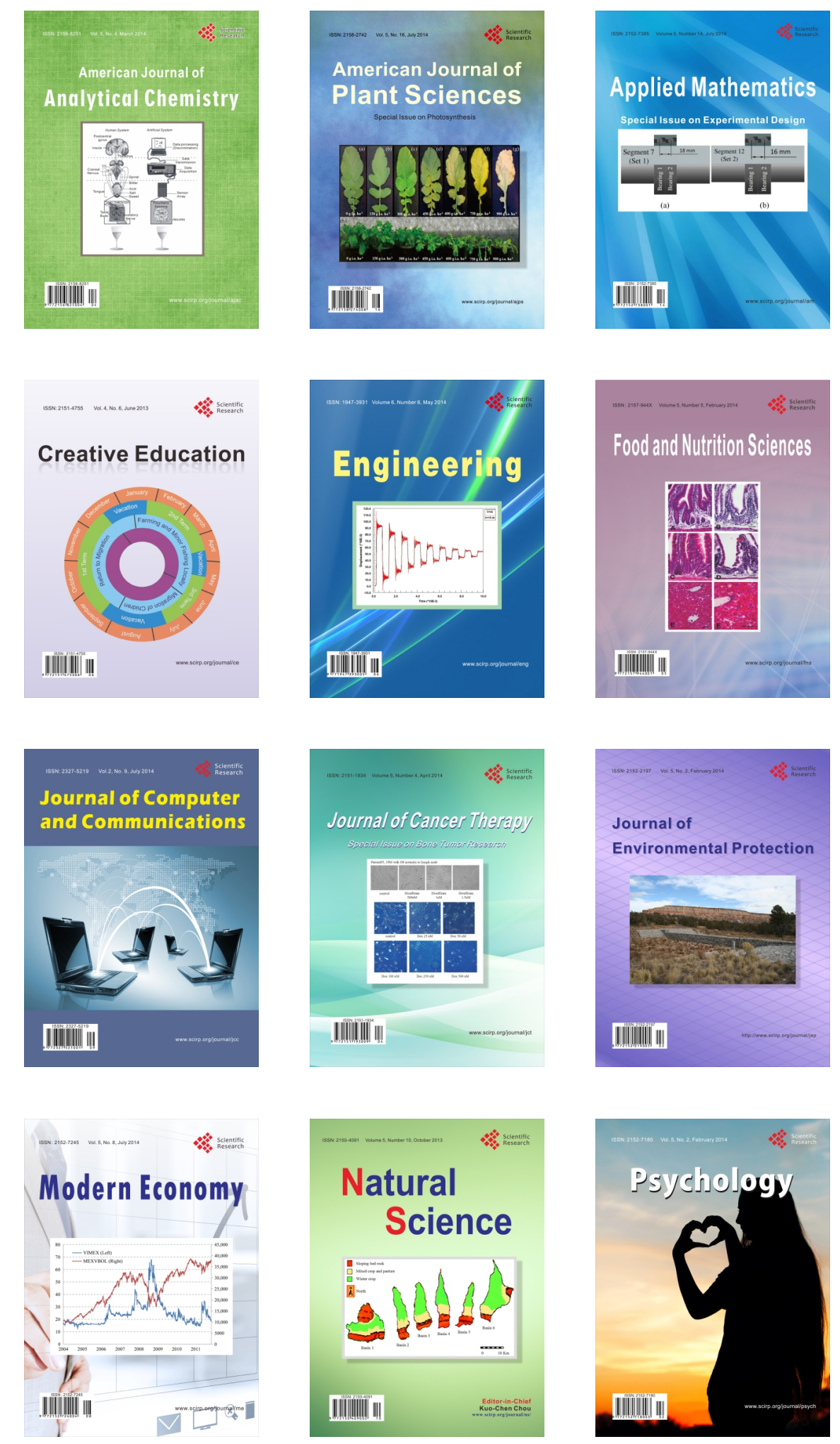